Tersedia online di: http://ejournal-balitbang.kkp.go.id/index.php/jra

\title{
PENGARUH GENOTIPE, LINGKUNGAN, DAN INTERAKSI KEDUANYA TERHADAP STABILITAS PENAMPILAN FENOTIPIK IKAN MAS
}

\author{
Didik Ariyanto", Suharyanto, Flandrianto Sih Palimirmo, dan Yogi Himawan \\ Balai Riset Pemuliaan Ikan \\ Jl. Raya 2 Sukamandi, Subang 41263
}

(Naskah diterima: 31 Desember 2018; Revisi final: 30 Januari 2019; Disetujui publikasi: 31 Januari 2019)

\begin{abstract}
ABSTRAK
Ikan mas (Cyprinus carpio) merupakan komoditas budidaya yang mudah beradaptasi dengan berbagai kondisi lingkungan. Penelitian ini bertujuan mempelajari pengaruh genotipe, lingkungan, dan interaksi antara genotipe dengan lingkungan terhadap stabilitas penampilan fenotipik ikan mas dalam kegiatan budidaya. Rancangan percobaan menggunakan rancangan faktorial $3 \times 5$ dengan lima ulangan. Lima strain ikan mas, yaitu Rajadanu, Sutisna, Majalaya, Wildan, dan Sinyonya dipelihara secara komunal di dalam tiga model wadah budidaya, yaitu kolam beton, kolam jaring, dan kolam tanah, selama 90 hari. Hasil penelitian menunjukkan bahwa penampilan fenotipik ikan mas dipengaruhi oleh genotipe, lingkungan dan interaksi kedua faktor tersebut. Strain Sutisna dan Wildan mempunyai nilai sintasan yang paling baik di semua lingkungan dibanding tiga strain lainnya. Strain Sutisna mempunyai pertumbuhan terbaik di kolam tanah sedangkan strain Wildan di kolam jaring. Hal ini menyebabkan kedua strain tersebut menghasilkan biomassa panen terbaik pada lingkungan yang berbeda. Hasil analisis stabilitas menunjukkan bahwa kelima strain ikan mas dalam penelitian ini relatif tidak stabil dan mempunyai respons yang berbeda jika dipelihara pada lingkungan yang berbeda. Strain Wildan dan Rajadanu merupakan strain ikan mas yang mempunyai respons terhadap perbedaan lingkungan paling tinggi. Strain dengan karakteristik tersebut akan mempunyai performa terbaik pada lokasi dan kondisi pemeliharan yang sesuai dengan kebutuhannya, tetapi mempunyai penampilan fenotipik yang rendah jika kondisi lingkungan budidayanya tidak sesuai. Strain Sutisna, Sinyonya, dan Majalaya merupakan strain ikan mas dengan daya responsi terhadap lingkungan lebih rendah. Karakteristik ini menyebabkan penampilan fenotipik ketiga strain tersebut relatif stabil pada semua lokasi dan kondisi budidaya, meskipun tidak bisa mencapai hasil yang maksimal.
\end{abstract}

KATA KUNCl: genotipe; ikan mas; interaksi G><E; lingkungan; penampilan fenotipik

ABSTRACT: The effect of genotype, environment, and their interaction in phenotypic performance stability of common carp. By: Didik Ariyanto, Suharyanto, Flandrianto Sih Palimirmo, and Yogi Himawan

Common carp (Cyprinus carpio) is known as fish species highly adaptable to various environmental conditions. This study aimed to evaluatethe effect of genotype, environment, and their interaction in phenotypic performance stability of common carp. The experimental design used a $3 \times 5$ factorial design with five repetitions. Five strains of common carp, namely Rajadanu, Sutisna, Majalaya, Wildan, and Sinyonya were stocked communally for 90 days in three culture systems: concretepond, net cage pond, and earthen pond. The result showed that the phenotypic performance of common carp was influenced by genotype, environment, and their interaction. Sutisna and Wildan strains have a higher survival rate compared to other strains in all culture systems. Sutisna and Wildan strains have the best growth performance in the earthen pond and net cage pond, respectively. Both strains also have the highest biomass production at harvest in all culture systems. Based on the stability performance analysis, W ildan and Rajadanu have the highest response to the different environmental conditions. Strains with this characteristic perform best in different locations or culture systems as long as the environmental conditions are suitable. However, these fish will likely perform poor in the unsuitable culture environment. Sutisna, Sinyonya, and Majalaya are carp strains with lower responsiveness to environmental change. Such characteristic causes the phenotypic performance of these three strains cannot achieve the maximum results, yet it is relatively stable in all locations.

\section{KEYWORDS: genotype; common carp; environment; $\mathrm{G}\rangle\langle\mathrm{E}$ interaction; genotype; phenotypic performance}

\footnotetext{
\# Korespondensi: Balai Riset Pemuliaan Ikan.

Jl. Raya 2 Sukamandi, Subang 41263, Indonesia.

Tel. + 62260520500

E-mail: didik_ski@yahoo.com
} 


\section{PENDAHULUAN}

Ikan mas (Cyprinus carpio) merupakan salah satu komoditas ekonomis budidaya ikan air tawar secara nasional dan internasional. Ikan mas bersifat kosmopolit, artinya mempunyai kemampuan adaptasi yang luas terhadap kondisi lingkungan yang berbeda. Kemampuan tersebut menyebabkan budidaya ikan mas tersebar cukup luas, mulai dari dataran rendah hingga dataran tinggi. Namun demikian, kondisi geografi dan agroklimatologi yang berbeda antara masing-masing lokasi diduga berpengaruh terhadap penampilan fenotipik dan tingkat produktivitas budidaya ikan mas. Dijelaskan oleh Tave (1993; 1995), Hardjosubroto (1994), dan Noor (2000) bahwa penampilan fenotipik suatu organisme ditentukan oleh faktor internal (genetik) dan dipengaruhi oleh faktor eksternal (lingkungan). Organisme dengan kualitas genetik yang baik akan menghasilkan penampilan fenotipik yang optimal jika didukung oleh lingkungan yang sesuai dengan kebutuhan organisme tersebut. Namun demikian, organisme dengan kualitas genetik yang rendah tidak akan menghasilkan penampilan fenotipik optimal meskipun kualitas lingkungannya diperbaiki. Dalam beberapa kasus, interaksi yang mungkin terjadi antara faktor genetik dengan lingkungan tempat organisme tersebut berkembang juga memengaruhi penampilan fenotipiknya.

Ikan mas di Indonesia dikenal beberapa jenis atau strain yang dominan dipelihara oleh pembudidaya, antara lain strain Majalaya, Rajadanu, Sutisna, Wildan, dan Sinyonya. Gustiano (1994), Hardjamulia et al. (1997), Arifin \& Kurniasih (2007), dan Ath-thar et al. (2011) melaporkan bahwa masing-masing strain yang digunakan dalam kegiatan budidaya mempunyai penampilan fenotipik yang berbeda, seperti pada karakter laju pertumbuhan, bobot panen, sintasan, rasio konversi pakan, dan lainnya. Data empiris juga menunjukkan bahwa terdapat variasi penampilan fenotipik pada budidaya ikan mas yang dilakukan di lokasi dan model budidaya yang berbeda (Nugroho, 2012; Ardi, 2013; Himawan et al., 2017). Variasi produksi antar lokasi dan model wadah budidaya tersebut diduga disebabkan adanya perbedaan kondisi geografis, agro-klimatologis, dan teknologi budidaya yang dikembangkan. Perbedaan kondisi lingkungan budidaya ini selanjutnya berdampak terhadap respons dari genotipe ikan mas yang tidak sama sehingga menghasilkan penampilan fenotipik yang bervariasi. Dalam rangka mendapatkan informasi mengenai variasi penampilan fenotipik ikan mas yang lebih menyeluruh, maka penelitian yang secara spesifik membahas pengaruh genotipe yang berbeda, serta kondisi lingkungan budidaya yang bervariasi perlu dilakukan.
Beberapa metode pragmatis untuk menjelaskan dan menginterpretasikan respons genotipe terhadap variasi lingkungannya telah banyak dikembangkan. Metode-metode tersebut melibatkan analisis statistik untuk mengukur adaptabilitas dan stabilitas genotipe terhadap variasi lingkungan menurut model yang berbeda. Salah satu model yang paling banyak digunakan pada bidang pertanian secara umum adalah model yang dikembangkan oleh Eberhart \& Russell (1966). Model ini dikembangkan berdasarkan pada regresi penampilan genotipe terhadap indeks lingkungannya. Penelitian ini bertujuan untuk menguji pengaruh genotipe, lingkungan, serta interaksi antara genotipe dengan lingkungan terhadap penampilan fenotipik lima strain ikan mas budidaya.

\section{BAHAN DAN METODE}

\section{Ikan Uji}

Bahan utama penelitian ini adalah lima strain ikan mas yang dominan dibudidaya oleh masyarakat, yaitu Rajadanu (Kuningan), Sutisna (Kuningan), Majalaya (Bandung), Wildan (Cianjur), dan Sinyonya (Pandeglang). Benih yang digunakan adalah hasil pemijahan induk koleksi yang diperoleh dari masingmasing lokasi tersebut. Benih ikan mas tersebut berumur lima bulan dari menetas dengan ukuran bobot $43,9 \pm 27,7 \mathrm{~g}$ dan panjang standar $102,0 \pm 21,6 \mathrm{~mm}$. Jumlah benih yang digunakan sebanyak 2.875 ekor. Semua individu diberi tanda (marker) dengan cara memotong atau mencabut duri punggung dengan urutan berbeda pada masing-masing strain.

\section{Rancangan Percobaan}

Rancangan percobaan yang digunakan adalah rancangan faktorial dua faktor, terdiri atas faktor strain (genotipe) dan faktor model wadah budidaya (lingkungan). Faktor strain terdiri atas lima strain, yaitu: (1) Rajadanu, (2) Sutisna, (3) Majalaya, (4) Wildan, dan (5) Sinyonya. Faktor model wadah budidaya terdiri atas tiga model, yakni: (1) kolam beton, (2) kolam jaring, dan (3) kolam tanah. Semua perlakuan percobaan diulang sebanyak lima kali.

\section{Metode Pemeliharaan}

Model wadah budidayayang digunakan yaitu, kolam beton ukuran $25 \mathrm{~m}^{2}$ dengan kedalaman air $70-80 \mathrm{~cm}$, kolam jaring ukuran $25 \mathrm{~m}^{2}$ dengan kedalaman air 80$100 \mathrm{~cm}$, dan kolam tanah ukuran $200 \mathrm{~m}^{2}$ dengan kedalaman air 40-60 cm. Pada semua wadah budidaya terdapat aliran air dengan kecepatan rendah, antara 0,2-1,0 L/detik. Khusus pada kolam beton, model wadah budidaya dilengkapi jaringan aerasi 
menggunakan blower dengan lima titik aerasi per kolam. Titik-titik aerasi ini merupakan bagian dari sistem aerasi menggunakan blower dengan kapasitas 240 volt / 1.100 watt, yang secara keseluruhan terbagi dalam 40 kolam beton.

Penebaran benih ikan mas dilakukan secara komunal antar lima strain di ketiga model wadah budidaya, artinya di dalam setiap wadah budidaya ditebar benih ikan dari lima strain ikan mas dalam proporsi jumlah yang sama. Padat penebaran yang diterapkan sebesar 0,07 ekor $/ \mathrm{m}^{3}$ di kolam beton; 0,09 ekor/m $\mathrm{m}^{3}$ di kolam jaring; dan 0,03 ekor/m³ di kolam tanah. Selama 90 hari pemeliharaan, benih diberi pakan pelet dengan kandungan protein 28\%30\% Pakan diberikan secara satiasi setiap pagi dan sore.

\section{Parameter dan Analisis Data}

Parameter kualitas air media pemeliharaan ikan yang diamati adalah suhu, oksigen terlarut, nilai $\mathrm{pH}$, amonia, dan nitrit. Kualitas air diamati setiap dua minggu sekali menggunakan alat pengukur kualitas air elektrik (water quality checker). Pengamatan dilakukan di empat titik setiap wadah pemeliharaan, kemudian hasilnya dirata-rata. Data kualitas air disajikan dalam nilai rata-rata minimal dan maksimal, dan dianalisis secara deskriptif.

Penampilan fenotipik yang diamati pada akhir pengujian adalah karakter-karakter terkait pertumbuhan dan produktivitas ikan mas, yaitu panjang, tinggi, tebal, bobot, sintasan, dan biomassa panen. Jumlah sampel untuk pengukuran karakter terkait pertumbuhan sebanyak 30\%dari jumlah benih saat ditebar di masing-masing model wadah budidaya. Nilai sintasan dihitung dari jumlah benih yang hidup pada saat panen dibagi jumlah penebaran, dan dikali $100 \%$ Biomassa panen dianalisis dengan mengalikan jumlah individu yang hidup dengan bobot rata-rata masing-masing strain.

Penentuan keunggulan genotipe ikan mas yang diuji pada satu lingkungan tertentu dilakukan melalui uji $\mathrm{F}$ menggunakan program Excel 2010. Pendugaan interaksi genetik dengan lingkungan dilakukan dengan analisis varian terhadap data gabungan setiap karakter di semua lokasi. Sebelum dilakukan analisis varian secara gabungan, terlebih dahulu dilakukan uji homogenitas variasi galat untuk lima lokasi dengan menggunakan uji Bartlett secara manual menggunakan program Excel 2010. Analisis stabilitas penampilan fenotipik kelima strain ikan mas pada model wadah budidaya berbeda dilakukan mengikuti prosedur Eberhart \& Russel (1966) secara manual menggunakan program Excel 2010.

\section{HASIL DAN BAHASAN}

\section{Lingkungan Budidaya}

Parameter kualitas air di tiga model wadah budidaya pada penelitian ini disajikan pada Tabel 1 . Sebagai pembanding, disajikan nilai baku mutu air untuk kegiatan budidaya ikan mas.

Hasil analisis kuaitas air media budidaya di tiga model tersebut menunjukkan nilai yang tidak berbeda. Namun, model kolam beton memiliki fluktuasi suhu, nilai $\mathrm{pH}$, kandungan ammonia, dan nitrit yang paling besar dibanding kedua model wadah budidaya lainnya. Selain itu, kandungan oksigen pada kolam beton juga paling rendah. Jika dibandingkan dengan nilai baku mutu air untuk budidaya ikan mas, parameter kualitas air media pemeliharaan ikan mas selama penelitian telah memenuhi standar yang disyaratkan. Namun demikian, kandungan oksigen terlarut relatif rendah pada waktu-waktu tertentu terutama pada waktu dini hari. Demikian juga dengan kandungan nitrit yang relatif tinggi pada akhir kegiatan pemeliharaan sebesar $0,07-0,10 \mathrm{mg} / \mathrm{L}$.

Hal yang cukup menarik adalah nilai kandungan oksigen di kolam beton yang tidak pernah mencapai nilai optimal standar budidaya. Luasan permukaan air pada kolam beton sebesar $25 \mathrm{~m}^{2}$ diduga tidak cukup luas untuk terjadinya difusi oksigen dari udara ke air. Meskipun luasan permukaan air pada kolam jaring juga $25 \mathrm{~m}^{2}$, tetapi jaring tersebut terpasang pada kolam dengan luas secara keseluruhan sebesar $6.000 \mathrm{~m}^{2}$. Hal ini mengakibatkan terjadinya difusi oksigen ke dalam air kolam yang dibantu oleh adanya angin di permukaan perairan, sehingga kandungan oksigen maksimal di kolam jaring lebih tinggi. Kondisi yang sama juga terjadi pada kolam tanah dengan luasan permukaan air sebesar $400 \mathrm{~m}^{2}$.

Selain disebabkan oleh luasan permukaan kolam yang relatif kecil, rendahnya nilai oksigen terlarut di kolam beton juga disebabkan oleh relatif tingginya padat penebaran ikan sebesar $0,07 \mathrm{ekor} / \mathrm{m}^{2}$. Hal ini mengakibatkan konsumsi oksigen oleh ikan yang relatif banyak sehingga kadar oksigen bebas dalam perairan menjadi sedikit. Meskipun padat penebaran ikan di kolam jaring lebih besar, yaitu 0,09 ekor $/ \mathrm{m}^{2}$, tetapi luasan kolam sebesar $6.000 \mathrm{~m}^{2}$ diduga sangat berpengaruh baik terhadap ketersediaan oksigen terlarut dalam perairan tersebut.

\section{Penampilan Fenotipik}

Penampilan fenotipik lima strain ikan mas yang dipelihara di tiga model wadah budidaya berbeda selama tiga bulan disajikan pada Tabel 2, sedangkan 
Tabel 1. Kualitas air media budidaya ikan mas di kolam beton, kolam jarring, dan kolam tanah selama penelitian

Table 1. Water quality in concrete, net cage, and earthen ponds during rearing period

\begin{tabular}{lcccc}
\hline \multicolumn{1}{c}{$\begin{array}{c}\text { Parameter } \\
\text { Parameters }\end{array}$} & $\begin{array}{c}\text { Kolam beton } \\
\text { Concrete pond }\end{array}$ & $\begin{array}{c}\text { Kolam jaring } \\
\text { Net cage on pond }\end{array}$ & $\begin{array}{c}\text { Kolam tanah } \\
\text { Earthen pond }\end{array}$ & $\begin{array}{c}\text { Baku mutu air budidaya ikan } \\
\text { Standart in fish culture }\end{array}$ \\
\hline Suhu (Temperature) $\left({ }^{\circ} \mathrm{C}\right)$ & $27.4-31.9$ & $28.0-31.2$ & $27.5-31.8$ & $25.0-30.0$ \\
Oksigen terlarut & $0.2-3.2$ & $0.6-5.2$ & $0.3-6.5$ & $>5.0$ \\
Dissolved oxygen (mg/L) & $6.5-8.0$ & $6.5-7.5$ & $6.8-7.3$ & $6.5-8.5$ \\
Nilai pH (pH value) & $0-0.08$ & $0-0.05$ & $0-0.03$ & $<1$ \\
Amonia (Ammonia) (mg/L) & $0-0.1$ & $0-0.07$ & $0-0.1$ & $<0.06$ \\
Nitrit (Nitrite) (mg/L) & 0 & & & \\
\hline
\end{tabular}

Tabel 2. Penampilan fenotipik lima strain ikan mas yang dipelihara di tiga model wadah pemeliharaan yang berbeda selama tiga bulan

Table 2. Phenotypic performance of five strains of common reared in three different culture systems for three months

\begin{tabular}{|c|c|c|c|c|c|c|c|}
\hline \multirow{2}{*}{\multicolumn{2}{|c|}{$\begin{array}{l}\text { Karakter fenotipik } \\
\text { Phenotypic character }\end{array}$}} & \multicolumn{6}{|c|}{ Model wadah budidaya (Culture system models) } \\
\hline & & $\begin{array}{l}\text { Kolam beton } \\
\text { Concrete pond }\end{array}$ & $\begin{array}{c}\mathrm{KV} / \mathrm{CV} \\
(\%)\end{array}$ & $\begin{array}{l}\text { Kolam jaring } \\
\text { Net cage on pond }\end{array}$ & $\begin{array}{c}\mathrm{KV} / \mathrm{CV} \\
(\%)\end{array}$ & $\begin{array}{l}\text { Kolam tanah } \\
\text { Earthen pond }\end{array}$ & $\begin{array}{c}\mathrm{KV} / \mathrm{CV} \\
(\%)\end{array}$ \\
\hline \multirow{5}{*}{$\begin{array}{l}\text { Panjang badan } \\
\text { Body length }(\mathrm{mm})\end{array}$} & Rajadanu & $14.01^{\mathrm{a}}$ & 13.12 & $15.74^{\mathrm{a}}$ & 7.80 & $13.54^{\mathrm{a}}$ & 10.41 \\
\hline & Sutisna & $14.60^{\mathrm{a}}$ & 7.11 & $16.20^{\mathrm{a}}$ & 7.65 & $16.92^{b}$ & 7.75 \\
\hline & Majalaya & $14.93^{\mathrm{a}}$ & 17.12 & $15.46^{\mathrm{a}}$ & 8.12 & $16.82^{\mathrm{ab}}$ & 11.20 \\
\hline & Wildan & $14.76^{\mathrm{a}}$ & 9.52 & $18.13^{\mathrm{a}}$ & 10.20 & $15.00^{\mathrm{ab}}$ & 4.70 \\
\hline & Sinyonya & $12.59^{\mathrm{a}}$ & 15.17 & $14.74^{\mathrm{a}}$ & 12.98 & $15.65^{\mathrm{ab}}$ & 6.30 \\
\hline \multirow{5}{*}{$\begin{array}{l}\text { Tinggi badan } \\
\text { Body depth (mm) }\end{array}$} & Rajadanu & $4.92^{\mathrm{a}}$ & 1.84 & $5.88^{\mathrm{ab}}$ & 7.07 & $4.91^{\mathrm{a}}$ & 10.56 \\
\hline & Sutisna & $5.68^{b}$ & 9.97 & $6.06^{\mathrm{ab}}$ & 8.77 & $6.33^{b}$ & 5.55 \\
\hline & Majalaya & $5.77^{\mathrm{ab}}$ & 19.01 & $5.89^{\mathrm{ab}}$ & 7.98 & $6.31^{b}$ & 12.42 \\
\hline & Wildan & $5.72^{b}$ & 7.16 & $7.09^{\mathrm{a}}$ & 12.93 & $5.76^{\mathrm{ab}}$ & 5.99 \\
\hline & Sinyonya & $4.93^{\mathrm{ab}}$ & 12.33 & $5.56^{\mathrm{b}}$ & 10.09 & $5.93^{b}$ & 6.84 \\
\hline \multirow{5}{*}{$\begin{array}{l}\text { Tebal badan } \\
\text { Body thickness (mm) }\end{array}$} & Rajadanu & $2.61^{a}$ & 6.88 & $3.12^{\mathrm{ab}}$ & 10.94 & $2.51^{\mathrm{a}}$ & 11.60 \\
\hline & Sutisna & $3.13^{\mathrm{ab}}$ & 13.89 & $3.29^{\mathrm{ab}}$ & 10.89 & $3.26^{b}$ & 6.11 \\
\hline & Majalaya & $2.87^{\mathrm{ab}}$ & 24.76 & $3.11^{\mathrm{ab}}$ & 8.09 & $3.16^{b}$ & 8.58 \\
\hline & Wildan & $3.05^{b}$ & 4.37 & $3.80^{\mathrm{a}}$ & 12.87 & $2.88^{\mathrm{ab}}$ & 9.02 \\
\hline & Sinyonya & $2.59^{\mathrm{ab}}$ & 16.38 & $2.94^{\mathrm{b}}$ & 8.84 & $2.93^{\mathrm{ab}}$ & 11.56 \\
\hline \multirow{5}{*}{$\begin{array}{l}\text { Bobot badan } \\
\text { Body weight (g) }\end{array}$} & Rajadanu & $90.67^{a}$ & 15.71 & $154.78^{\mathrm{ab}}$ & 25.25 & $90.00^{\mathrm{a}}$ & 26.57 \\
\hline & Sutisna & $126.80^{\mathrm{a}}$ & 26.14 & $158.28^{\mathrm{ab}}$ & 32.09 & $175.74^{b}$ & 23.75 \\
\hline & Majalaya & $136.55^{\mathrm{a}}$ & 51.73 & $136.32^{\mathrm{ab}}$ & 25.30 & $177.21^{b}$ & 35.75 \\
\hline & Wildan & $128.16^{\mathrm{a}}$ & 28.20 & $238.63^{\mathrm{a}}$ & 33.65 & $126.04^{\mathrm{ab}}$ & 16.70 \\
\hline & Sinyonya & $89.02^{\mathrm{a}}$ & 34.38 & $121.25^{\mathrm{b}}$ & 34.11 & $138.89^{b}$ & 17.32 \\
\hline
\end{tabular}

Keterangan: Huruf superskrip yang sama pada kolom yang sama pada masing-masing karakter menunjukkan tidak berbeda nyata $(P>0,05) ; K V=$ koefisien variasi

Note: $\quad$ The same superscript letter in the same column indicated insignificant differences $(P>0.05) ; C V=$ coeffisient of variation 
nilai sintasan dan biomassa pada saat panen kelima strain ikan mas tersebut disajikan pada Tabel 3.

Lima strain ikan mas yang dipelihara di dalam tiga model wadah budidaya yang berbeda mempunyai penampilan fenotipik yang beragam. Pada pemeliharaan di kolam beton, karakter panjang dan bobot badan antar strain tidak berbeda, sedangkan karakter tinggi dan tebal badan berbeda nyata. Pada pemeliharaan di kolam jaring, hanya karakter panjang badan yang tidak berbeda nyata, tetapi tiga karakter lainnya, yaitu tinggi, tebal, dan bobot badan berbeda nyata. Pada pemeliharaan di kolam tanah, semua karakter biometrik yang diukur berbeda nyata antar strain.

Tabel 3 menunjukkan bahwa nilai sintasan kelima strain ikan mas yang dipelihara di kolam beton dan kolam jaring berbeda nyata, sedangkan pada kolam tanah tidak berbeda. Namun demikian, biomassa panen kelima strain ikan mas yang dipelihara di kolam jaring dan kolam tanah berbeda nyata, sedangkan di

Tabel 3. Nilai sintasan dan biomassa lima strain ikan mas yang dipelihara di tiga model wadah pemeliharaan yang berbeda selama tiga bulan

Table 3. Survival rate and biomass of five strains of common carp which reared in three different culture systems for three months

\begin{tabular}{|c|c|c|c|c|c|c|c|}
\hline \multirow{2}{*}{\multicolumn{2}{|c|}{$\begin{array}{l}\text { Karakter fenoti pik } \\
\text { Phenotypic character }\end{array}$}} & \multicolumn{6}{|c|}{ Model wadah budidaya (Culture system models) } \\
\hline & & $\begin{array}{l}\text { Kolam beton } \\
\text { Concrete pond }\end{array}$ & $\begin{array}{c}\text { KV } \\
\text { CV (\%) }\end{array}$ & $\begin{array}{l}\text { Kolam jaring } \\
\text { Net cage on pond }\end{array}$ & $\begin{array}{c}\text { KV } \\
\text { CV (\%) }\end{array}$ & $\begin{array}{l}\text { Kolam tanah } \\
\text { Earthen pond }\end{array}$ & $\begin{array}{c}\text { KV } \\
\text { CV (\%) }\end{array}$ \\
\hline \multirow{5}{*}{$\begin{array}{l}\text { Sintasan } \\
\text { Survival rate }(\%)\end{array}$} & Rajadanu & $88.0^{\mathrm{a}}$ & 12.4 & $90.0^{\mathrm{ab}}$ & 24.8 & $72.0^{\mathrm{a}}$ & 36.0 \\
\hline & Sutisna & $100.0^{b}$ & 0.0 & $100.0^{\mathrm{a}}$ & 0.0 & $94.0^{\mathrm{a}}$ & 14.3 \\
\hline & Majalaya & $80.0^{\mathrm{a}}$ & 17.7 & $92.5^{\mathrm{ab}}$ & 12.1 & $90.0^{\mathrm{a}}$ & 19.2 \\
\hline & Wildan & $100.0^{b}$ & 0.0 & $100.0^{\mathrm{a}}$ & 0.0 & $90.0^{\mathrm{a}}$ & 24.8 \\
\hline & Sinyonya & $92.0^{\mathrm{ab}}$ & 11.9 & $87.5^{\mathrm{b}}$ & 10.1 & $82.0^{\mathrm{a}}$ & 13.4 \\
\hline \multirow{5}{*}{$\begin{array}{l}\text { Biomassa } \\
\text { Biomass (kg) }\end{array}$} & Rajadanu & $10.0^{\mathrm{a}}$ & 21.4 & $29.0^{\mathrm{ab}}$ & 40.2 & $17.2^{\mathrm{a}}$ & 46.8 \\
\hline & Sutisna & $15.9^{\mathrm{a}}$ & 26.1 & $31.7^{\mathrm{ab}}$ & 32.1 & $41.5^{b}$ & 30.6 \\
\hline & Majalaya & $14.0^{\mathrm{a}}$ & 54.6 & $25.7^{\mathrm{ab}}$ & 32.4 & $41.0^{\mathrm{ab}}$ & 47.4 \\
\hline & Wildan & $16.0^{\mathrm{a}}$ & 28.2 & $47.7^{\mathrm{a}}$ & 33.6 & $29.0^{\mathrm{ab}}$ & 34.4 \\
\hline & Sinyonya & $10.4^{\mathrm{a}}$ & 42.2 & $21.5^{b}$ & 42.1 & $28.5^{\mathrm{ab}}$ & 21.3 \\
\hline
\end{tabular}

Keterangan: Huruf superskrip yang sama pada kolom yang sama pada masing-masing karakter menunjukkan tidak berbeda nyata $(P>0,05) ; K V=$ koefisien variasi

Note: $\quad$ The same superscript letter in the same column indicated insignificant differences $(\mathrm{P}>0.05) ; \mathrm{CV}=$ coeffisient of variation

Tabel 4. Nilai P pada analisis sidik ragam karakter fenotipik lima strain ikan mas yang dipelihara di tiga model wadah budidaya berbeda selama tiga bulan

Table 4. P value in analysis of variance for phenotypic character of five strains of common carp reared in three different culture systems for three months

\begin{tabular}{lccc}
\hline $\begin{array}{c}\text { Sumber keragaman } \\
\text { Source of diversity }\end{array}$ & $\begin{array}{c}\text { Strain } \\
\text { Strains (G) }\end{array}$ & $\begin{array}{c}\text { Wadah budidaya } \\
\text { Culture system (E) }\end{array}$ & $\begin{array}{c}\text { Interaksi } \\
\text { Interaction (GxE) }\end{array}$ \\
\hline Panjang (Length) & 0.004 & 0.000 & 0.015 \\
Tinggi (Depth) & 0.000 & 0.000 & 0.014 \\
Tebal (Thickness) & 0.000 & 0.000 & 0.044 \\
Bobot (W eight) & 0.003 & 0.001 & 0.008 \\
Sintasan (Survival rate) & 0.017 & 0.261 & 0.471 \\
Biomassa (Biomass) & 0.000 & 0.032 & 0.020 \\
\hline
\end{tabular}

Keterangan (Note): $\mathrm{G}$ = genotipe (Genotype), $\mathrm{E}=$ lingkungan (environment) 
kolam beton tidak berbeda. Hal ini mengindikasikan adanya pengaruh penggunaan strain dan model wadah budidaya yang berbeda, serta interaksi kedua faktor tersebut terhadap penampilan fenotipik ikan mas. Dalam rangka mengklarifikasi indikasi tersebut, pada Tabel 4 disajikan hasil analisis sidik ragam karakter fenotipik lima strain ikan mas tersebut.

Hasil analisis sidik ragam menunjukkan bahwa penampilan fenotipik ikan mas secara nyata dipengaruhi oleh strain atau genotipe (G), wadah budidaya atau lingkungan (E) dan interaksi antar kedua faktor tersebut $(\mathrm{G}><\mathrm{E})$. Adanya pengaruh faktor genetik diindikasikan dengan perbedaan penampilan fenotipik antar genotipe yang dipelihara pada lingkungan yang sama, sedangkan adanya pengaruh lingkungan diindikasikan dengan perbedaan penampilan fenotipik suatu genotipe yang dipelihara pada lingkungan yang berbeda-beda. Hasil penelitian ini sesuai dengan pendapat Tave (1993; 1995), Hardjosubroto (1994), dan Noor (2000) yang menjelaskan bahwa penampilan fenotipik suatu genotipe dapat dipengaruhi oleh faktor genetik, lingkungan, serta kemungkinan adanya interaksi antara kedua faktor tersebut.

Penampilan fenotipik yang berbeda merupakan ekspresi dari masing-masing strain dalam merespons kondisi lingkungan wadah budidaya yang berbeda. Ekspresi dari masing-masing individu maupun populasi dalam merespons kondisi lingkungan yang bervariasi dapat berupa penampilan karakter-karakter biometrik hingga kemampuan bertahan hidup yang berbeda. Genotipe yang mampu bertahan hidup pada kondisi lingkungan yang kurang menguntungkan umumnya mempunyai penampilan karakter biometrik yang lebih baik dibanding genotipe-genotipe yang kurang mampu bertahan hidup. Beberapa penelitian terkait pengaruh genotipe, lingkungan dan interaksi keduanya sudah dilaporkan, antara lain pada ikan nila (Eknath et al., 1993; Charo-Karisa et al., 2006; Khaw et al., 2012; Ariyanto \& Listiyowati, 2015), ikan salmon (Gjedrem, 2005), ikan cod (Bangera et al., 2015), ikan lele (Dunham et al., 1990), ikan mas (Wang \& Li, 2007), dan ikan kakap (Dupont-Nivet et al., 2008).

\section{Stabilitas Penampilan Fenotipik}

Hasil analisis stabilitas fenotipik berdasarkan karakter bobot badan lima strain ikan mas pada lingkungan yang berbeda disajikan pada Tabel 5 . Sebagai data dukung, pada Gambar 1 disajikan estimasi biomassa panen lima strain ikan mas yang dipelihara pada kondisi lingkungan berbeda.

Tabel 5 menunjukkan bahwa nilai standar deviasi $\left(S d^{2}\right)$ dari nilai koefisien regresi (bi) kelima strain ikan mas dalam penelitian ini tidak sama dengan satu. Artinya, kelima strain ikan mas tersebut tidak menunjukkan stabilitas karakter fenotipik yang baik jika dipelihara pada lokasi yang berbeda. Berdasarkan nilai koefisien regresinya, strain Rajadanu dan Wildan merupakan strain ikan mas yang mempunyai daya responsi terhadap perbedaan lingkungan paling tinggi (bi>1), sedangkan strain Sutisna, Sinyonya, dan Majalaya merupakan strain dengan daya responsi terhadap lingkungan lebih rendah $(\mathrm{bi}<1)$. Hasil ini didukung dengan analisis estimasi produksi masingmasing strain yang dipelihara pada model wadah budidaya yang berbeda pada Gambar 1. Berdasarkan Gambar 1 terlihat bahwa strain Rajadanu dan Wildan mempunyai peningkatan produksi yang signifikan jika dipelihara pada lingkungan yang lebih baik, sedangkan ketiga strain lainnya mempunyai peningkatan produksi yang tidak terlalu signifikan meskipun kondisi lingkungannya diperbaiki.

Evaluasi penampilan fenotipik dari genotipe unggul ikan bertujuan untuk mendapatkan genotipe atau varietas ikan yang mempunyai karakter terbaik pada lokasi atau model wadah budidaya yang bervariasi. Karakter yang baik berdampak terhadap hasil atau produksi yang tinggi sebagai target akhir kegiatan budidaya. Pada penelitian ini, pengaruh genotipe dan lingkungan lebih dominan dibanding pengaruh interaksi keduanya dalam mempengaruhi penampilan fenotipik populasi ikan mas. Namun demikian, adanya pengaruh interaksi faktor genotipe dengan lingkungan mengindikasikan bahwa tidak terdapat satu pun strain ikan mas yang mempunyai penampilan terbaik pada semua model wadah budidaya yang digunakan. Hasil ini juga didukung dengan analisis stabilitas penampilan fenotipik yang menunjukkan bahwa kelima strain ikan mas dalam penelitian ini mempunyai stabilitas yang rendah, jika dipelihara pada model budidaya yang berbeda. Ketidakstabilan penampilan fenotipik kelima strain ikan mas menunjukkan bahwa masing-masing strain ikan mas mempunyai respons yang berbeda ketika dibudidayakan pada lingkungan yang berbeda.

Strain Rajadanu merupakan genotipe ikan mas yang mempunyai nilai karakter-karakter terukur relatif lebih rendah dibanding strain lainnya. Namun demikian, strain Rajadanu berpotensi besar untuk menghasilkan produksi yang tinggi jika dipelihara pada lingkungan dan sistem budidaya yang tepat. Hal ini karena strain Rajadanu mempunyai daya responsi yang baik terhadap perubahan kondisi lingkungan. Model genotipe yang hampir sama adalah strain Wildan. Strain ini mempunyai penampilan fenotipik tidak terlalu baik pada kondisi lingkungan yang kurang menguntungkan, tetapi akan memberikan respons yang besar dengan adanya perubahan kondisi lingkungan yang lebih baik. Semakin 
Tabel 5. Nilai ragam $\left(\mathbf{o}^{2}\right)$, koefisien regresi (bi), dan standar deviasi $\left(S \mathrm{~d}_{\mathrm{i}}^{2}\right)$ karakter bobot badan lima strain ikan mas yang dipelihara pada tiga model wadah budidaya berbeda

Table 5. The variance $\left(\hat{o}^{2}\right)$, regression coefficient (bi) and deviation standard $\left(\mathrm{Sd}_{\mathrm{i}}{ }_{\mathrm{i}}\right)$ for body weight character of five strains of common carp reared in three different culture systems

\begin{tabular}{lcccccc}
\hline \multicolumn{1}{c}{ Strain } & $\boldsymbol{\sigma}^{2} \mathbf{v i}_{\mathbf{i}}$ & $\mathbf{b}_{\mathbf{i}}$ & $\mathbf{Y}_{\mathbf{i j}} \mathbf{X} \mathbf{I}_{\mathbf{i}}$ & $\mathbf{b}_{\mathbf{i}} \mathbf{X}\left(\mathbf{Y}_{\mathbf{i j}} \mathbf{X} \mathbf{I}_{\mathbf{i}}\right)$ & $\left.\boldsymbol{\sigma}^{2} \mathbf{v i}_{\mathbf{i}}-\mathbf{[} \mathbf{b}_{\mathbf{i}} \mathbf{X}\left(\mathbf{Y}_{\mathbf{i j}} \mathbf{\times} \mathbf{I}_{\mathbf{i}}\right)\right]$ & $\mathbf{S d}^{2}{ }_{\mathbf{i}}$ \\
\hline Rajadanu & $2,768.4$ & 1.3 & $1,448.9$ & $1,839.0$ & 929.4 & -81.4 \\
Sutisna & $1,230.3$ & 0.7 & 827.4 & 599.7 & 630.6 & $-181,0$ \\
Majalaya & $1,108.6$ & 0.1 & 90.4 & 7.2 & $1,101.4$ & $-24,0$ \\
Wildan & $8,294.1$ & 2.2 & $2,494.5$ & $5,450.7$ & $2,843.4$ & 556.6 \\
Sinyonya & $1,278.8$ & 0.7 & 846.7 & 628 & 650.8 & -174.3 \\
\hline
\end{tabular}

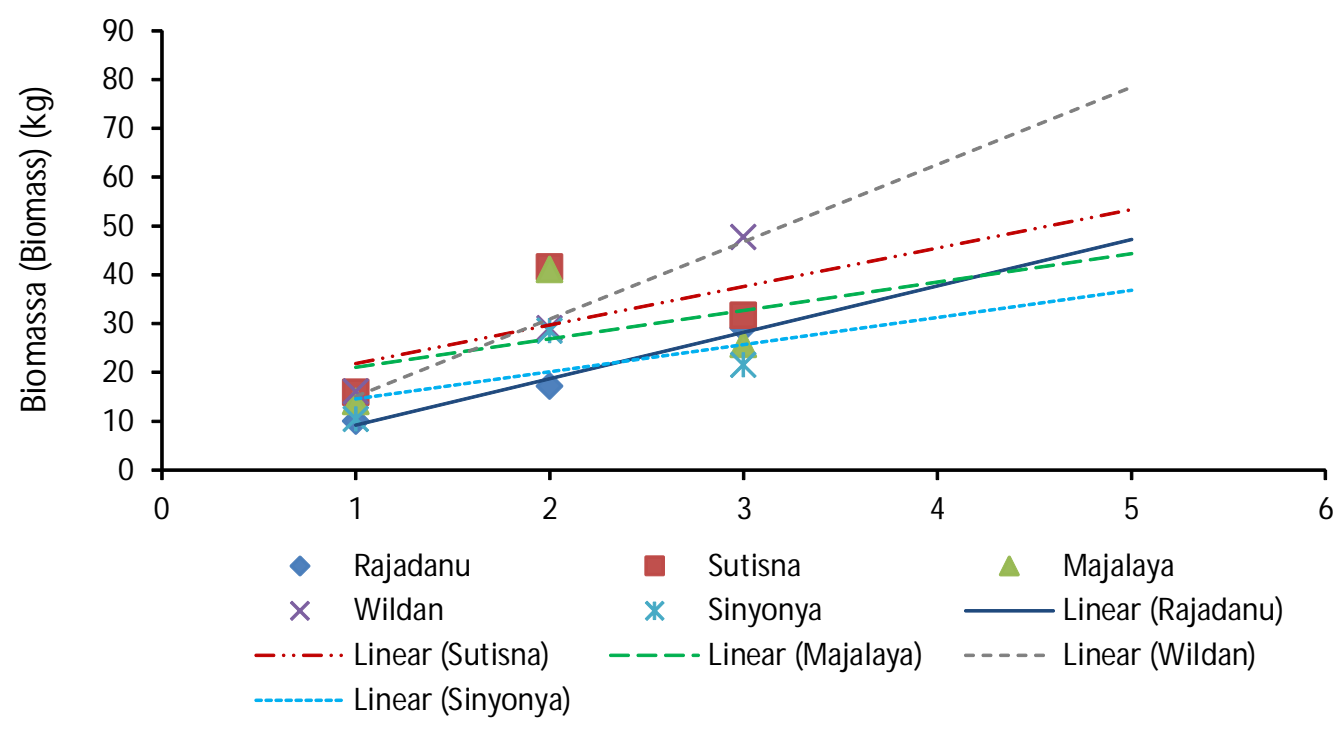

Lingkungan budidaya ikan

Fish culture environment

Gambar 1. Biomassa lima strain ikan mas yang dipelihara di tiga lingkungan berbeda.

Figure 1. The biomass of five strains of common carp reared in three different culture.

baik kondisi lingkungannya, maka genotipe tersebut akan mengekspresikan potensinya secara maksimal dalam bentuk penampilan fenotipik yang semakin bagus.

Genotipe lainnya yakni strain Majalaya, Sutisna, dan Sinyonya mempunyai penampilan fenotipik yang lebih baik dibandingkan strain Rajadanu dan Wildan. Meskipun genotipe seperti ini mempunyai daya adaptasi yang baik pada kondisi lingkungan yang kurang menguntungkan, tetapi kemungkinan tidak akan memberikan perbedaan hasil yang nyata meskipun kondisi lingkungannya diperbaiki. Dengan demikian, genotipe ini sesuai untuk lokasi-lokasi yang rentan dengan terjadinya perubahan kondisi lingkungan sehingga masih mampu mempertahankan penampilan fenotipiknya dengan baik.

Berdasarkan penelitian ini, strain Rajadanu dan Wildan merupakan genotipe yang spesifik lokasi, sedangkan strain Majalaya, Sutisna, dan Sinyonya merupakan genotipe yang mempunyai daya adaptasi yang luas. Dalam konteks budidaya, genotipe spesifik lokasi akan mempunyai penampilan fenotipik yang maksimal pada lingkungan yang baik dan sesuai dengan kebutuhannya, sedangkan genotipe dengan daya adaptasi luas mempunyai penampilan fenotipik yang relatif stabil pada semua lokasi budidaya. 


\section{KESIMPULAN}

Penampilan fenotipik ikan mas dipengaruhi oleh faktor genetik, lingkungan, dan interaksi antara kedua faktor tersebut. Strain Wildan dan Rajadanu merupakan genotipe yang beradaptasi baik pada lingkungan spesifik sehingga akan menghasilkan produksi maksimal pada kondisi lingkungan yang sesuai. Strain Majalaya, Sutisna, dan Sinyonya merupakan genotipe yang mampu beradaptasi dengan baik pada semua lingkungan, tetapi hasilnya tidak bisa maksimal seperti strain Wildan dan Rajadanu.

\section{UCAPAN TERIMA KASIH}

Penelitian ini dibiaya oleh APBN melalui DIPA No. 032.11.2.660052/2017 di Balai Riset Pemuliaan Ikan, Sukamandi tahun 2017. Penulis menyampaikan terima kasih kepada peneliti dan teknisi yang terlibat, serta kepada Dewan Redaksi Jurnal Riset Akuakultur dalam perbaikan makalah ini.

\section{DAFTAR ACUAN}

Ardi, I. (2013). Budidaya ikan sistem keramba jaring apung guna menjaga keberlanjutan lingkungan perairan Waduk Cirata. Media Akuakultur, 8(1), 2329.

Arifin, 0.Z. \& Kurniasih, T. (2007). Keragaan pertumbuhan benih ikan mas (Cyprinus carpio) strain Majalaya, lokal Bogor dan Rajadanu di kolam Cijeruk, Bogor-Jawa Barat. J. Riset Akuakultur, 2(2), 177-185.

Ariyanto, D. \& Listiyowati, N. (2015). Interaksi genotipe dengan lingkungan, adaptabilitas dan stabilitas penampilan fenotipik empat varietas unggul ikan nila (Oreochromis niloticus). J. Riset Akuakultur, 10(1), 1-9.

Ath-thar, M.H.F., Prakoso,V.A., \& Gustiano, R. (2011). Keragaan pertumbuhan hibridisasi empat strain ikan mas. Berita Biologi, 10(5), 613-620.

Bangera, R., Drangsholt, T.M.K., Nielsen, H.M., SaeLim, P., Ødegård, J., Puvanendran, V., Hansen, Ø.J., $\&$ M ortensen, A. (2015). Genotype by environment interaction for growth in Atlantic cod (Gadus morhua L.) in four farms of Norway. J. Mar. Sci. Eng., 3, 412-427.

Charo-Karisa, H., Komen, H., Reynolds, S., Rezk, M.A., Ponzoni, R.W., \& Bovenhuis, H. (2006). Genetic and environmental factors affecting growth of nile tilapia (Oreochromis niloticus) juveniles: Modelling spatial correlations between hapas. Aquaculture, 255, 586-596.

Dunham, R.A., Brummett, R.E., Ella, M.O., \& Smitherman, R.O. (1990). Genotype-environment interactions for growth of blue, channel and hy- brid catfish in ponds and cages at varying densities. Aquaculture, 85, 143-151.

Dupont-Nivet, M.,Vandeputte, M., Vergnet, A., Merdy, O., Haffray, P., Chavanne, H., \& Chatain, B. (2008). Heritabilities and $G><E$ interactions for growth in the European sea bass (Dicentrarchus labrax L.) using a marker-based pedigree. Aquaculture, 275, 81-87.

Eberhart, S.A. \& Russell, W.L. (1966). Stability parameters for comparing varietes. Crop Sci., 6, 36-40.

Eknath, A.E., Tayamen, M.M., Palada-de Vera, M.S., Danting, J.C., Reyes, R.A., Dinosio, E.E., Capili, J.B., Bolivar, H.L., Abella, T.A., Circa, A.V., Bentsen, H.B., Gjerde, B., Gjedrem, T., \& Pullin, R.S.V. (1993). Genetic improvement of farmed tilapia: the growth performance of eight strains of Oreochromis niloticus tested in different farm environments. Aquaculture, 111, 171-188.

Gjedrem, T. (2005). Genotype-environment interaction. In Gjedrem, T. (Ed.). Selection and Breeding Program in Aquaculture, p. 233-242.

Gustiano, R. (1994). Prospect of common carp culture in ruralareas. IARD Journal, 16(2), 24-28.

Hardjamulia, A., Asih, S., Supriyadi, H., \& Mucharam, B. (1997). Karakterisasi morfologis dan evaluasi beberapa plasma nutfah ikan mas (Cyprinus carpio). Bulletin Plasma Nutfah, 11(I), 24-28.

Hardjosubroto, W. (1994). Aplikasi pemuliabiakan ternak di lapangan. PT Grasindo Indonesia. Jakarta, $284 \mathrm{hlm}$.

Himawan, Y., Syahputra, K., \& Ariyanto, D. (2017). Performa pembesaran ikan mas Rajadanu (Cyprinus carpio) generasi ketiga hasil seleksi "walkback". J. Riset Akuakultur, 12(2), 121-129.

Khaw, H.L., Ponzoni, R.W., Hamzah, A., Abu-Bakar, K.R., \& Bijma, P. (2012). Genotype by production environment interaction in the GIFT strain of nile tilapia (Oreochromis niloticus). Aquaculture, 326-329, 53-60.

Noor, R.R. (2000). Genetika ternak. Jakarta: Penebar Swadaya, $200 \mathrm{hlm}$.

Nugroho, E. (2012). Keragaan produksi budidaya ikan mas di KJA Waduk Ir. H. Djuanda, Jatiluhur. Media Akuakultur, 7(1), 11-13.

Tave, D. (1993). Genetik for fish hatchery managers. NY, USA: The AVI Publ. Comp. Inc., $2^{\text {nd }}$ ed., 418 pp.

Tave, D. (1995). Selective breeding programs for medium size fish farms. Rome, FAO: FAO Fisheries Technical Paper, No. 352, 122 pp.

Wang, C. \& Li, S. (2007). Genetic effects and genotype $><$ environment interactions for growthrelated traits in common carp (Cyprinus carpio L). Aquaculture, 272, 267-272. 